\title{
Clinician's Capsules for CJEM 21(1)
}

A system-wide solution to antidote stocking in emergency departments: The Nova Scotia antidote program

Nancy G. Murphy, MD; D. Ruth Bona, RN CSPI; Theresa A. Hurley, B.Sc (Pharm) ACPR

doi: $10.1017 /$ cem.2017.400

\section{What is known about the topic?}

Inadequate access to antidote and standardized guidelines in emergency departments is a well-documented issue.

What did this study ask?

This study aimed to outline the complex process of planning and implementing a standardized provincial program for antidote stocking.

What did this study find?

A solution to inadequate antidote stocking is achievable and requires a system-wide approach with ongoing maintenance and surveillance.

Why does this study matter to clinicians?

Front-line healthcare providers need timely access to necessary antidotes, standardized, up-to-date guidelines for antidote administration with ongoing maintenance and surveillance.

An innovative short-stay healthcare model for treatment of uncomplicated vaso-occlusive crisis in adult sickle cell disease patients in Canada to reduce emergency department utilization

Andrew Binding, MD, MSc; Richard Ward, MSc, MRCP; Chai Phua, MD; Veronique Naessens, MD, CM; Tara O’Brien, MD; Sacha Bhatia, MD, MBA; Hayley Baranek, MPH; Husayn Marani, MSc; Geetha Mukerji, MD, MSc

doi: $10.1017 / \mathrm{cem} .2017 .413$

\section{What is known about the topic?}

Patients with sickle cell disease experiencing vasoocclusive crises often visit the emergency department (ED) for management.

What did this study ask?

This study sought to evaluate the feasibility of a short-stay model for treatment of vaso-occlusive crises outside of the ED.

What did this study find?

A short stay model improved patient satisfaction and decreased average time to first opiate dose to $23.5 \mathrm{~min}$ utes from 100.3 minutes (ED).
Why does this study matter to clinicians?

Delays in treatment in the ED exist for patients with vaso-occlusive crises and short-stay models can improve care delivery.

Evaluating mental health service use during and after emergency department visits in a multisite cohort of Canadian children and youth

Mario Cappelli, PhD; Paula Cloutier, MS; Amanda S. Newton, PhD; Eleanor Fitzpatrick, MN; Samina Ali, MD, CM; Kathryn A. Dong, MD, MSc, FRCP; Clare Gray, MD; Allison Kennedy, PhD; John S. Lyons, PhD; Christine Polihronis, PhD; Rhonda J. Rosychuk, $\mathrm{PhD}$.

doi: $10.1017 / \mathrm{cem} .2017 .416$

\section{What is known about the topic?}

Presentations for pediatric mental health are increasing yet little is known about presentation needs and access to services post emergency department (ED) discharge.

What did this study ask?

Objectives were to identify pediatric mental health needs at ED presentation, and the follow-up mental health services accessed by children and their families.

What did this study find?

Patients had substantial clinical morbidity, connected with services, satisfied with their ED visit, and accessed follow-up care within 1-month.

Why does this study matter to clinicians?

ED clinicians can play an important role in linking EDs to appropriate outpatient resources and educating patients.

The Quebec emergency department guide: A cross-sectional study to evaluate its use, perceived usefulness, and implementation in rural emergency departments

Richard Fleet, MD, PhD; Sandrine Hegg-Deloye, PhD; Julie Maltais-Giguère, $\mathrm{MSc}$

France Légaré, MD, $\mathrm{PhD}$; Mathieu Ouimet, $\mathrm{PhD}$; Julien Poitras, $\mathrm{MD}$; Alain Tanguay, MD; Patrick

Archambault, MD; Jean-Frédéric Lévesque, $\mathrm{PhD}$; Geneviève Simard-Racine, MD; Gilles Dupuis, PhD

doi: $10.1017 /$ cem.2017.423 
What is known about the topic?

Specific needs of rural populations require optimization of rural emergency departments and the Quebec Emergency Department Management Guide may provide guidance. What did this study ask?

What is the utility and perception of the Quebec Emergency Department Management Guide by rural health care management?

What did this study find?

While this guide is considered useful for rural EDs, it is not optimally known or used in rural EDs especially by physician management.

Why does this study matter to clinicians?

The Quebec Emergency Department Management Guide may provide novel recommendations designed to improve the organization and provision of quality care in all EDs. 